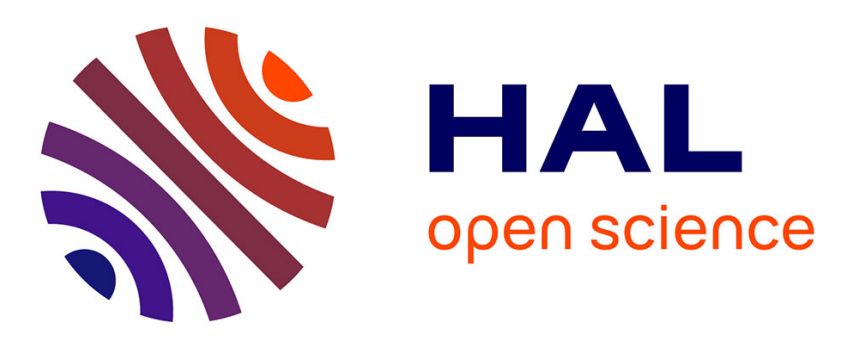

\title{
C14ORF179 encoding IFT43 is mutated in Sensenbrenner syndrome
}

Heleen H Arts, Ernie Bongers, Dorus Mans, Sylvia van Beersum, Machteld Oud, Emine Bolat, Liesbeth Spruijt, Elisabeth Cornelissen, Janneke Schuurs-Hoeijmakers, Nicole de Leeuw, et al.

\section{To cite this version:}

Heleen H Arts, Ernie Bongers, Dorus Mans, Sylvia van Beersum, Machteld Oud, et al.. C14ORF179 encoding IFT43 is mutated in Sensenbrenner syndrome. Journal of Medical Genetics, 2011, 48 (6), pp.390. 10.1136/jmg.2011.088864 . hal-00613258

\section{HAL Id: hal-00613258 https://hal.science/hal-00613258}

Submitted on 4 Aug 2011

HAL is a multi-disciplinary open access archive for the deposit and dissemination of scientific research documents, whether they are published or not. The documents may come from teaching and research institutions in France or abroad, or from public or private research centers.
L'archive ouverte pluridisciplinaire HAL, est destinée au dépôt et à la diffusion de documents scientifiques de niveau recherche, publiés ou non, émanant des établissements d'enseignement et de recherche français ou étrangers, des laboratoires publics ou privés. 


\section{C14ORF179 encoding IFT43 is mutated in Sensenbrenner syndrome}

Heleen H. Arts, ${ }^{1, *}$ Ernie M.H.F. Bongers, ${ }^{1}$ Dorus A. Mans, ${ }^{1}$ Sylvia E. van Beersum, ${ }^{1}$ Machteld M. Oud, ${ }^{1}$ Emine Bolat, ${ }^{1}$ Liesbeth Spruijt, ${ }^{1}$ Elisabeth A.M. Cornelissen, ${ }^{2}$ Janneke H. M. Schuurs-Hoeijmakers, ${ }^{1}$ Nicole de Leeuw, ${ }^{1}$ Valérie Cormier-Daire, ${ }^{3}$ Han G. Brunner, ${ }^{1}$ Nine V.A.M. Knoers, ${ }^{4}$ and Ronald Roepman ${ }^{1}$

${ }^{1}$ Department of Human Genetics, Nijmegen Centre for Molecular Life Sciences, Radboud University Nijmegen Medical Centre, Nijmegen, the Netherlands, ${ }^{2}$ Department of Pediatric Nephrology, Radboud University Nijmegen Medical Centre, Nijmegen, The Netherlands, ${ }^{3}$ INSERM U781 and Département de Génétique, Université Paris Descartes, Hôpital Necker-Enfants Malades, Paris, France,

${ }^{4}$ Department of Medical Genetics, Utrecht University Medical Center, Utrecht, the Netherlands.

HHA and EMHFB, and NVAMK and RR contributed equally to this work.

*Correspondence to:

Dr. Heleen H. Arts

Department of Human Genetics (855)

Radboud University Nijmegen Medical Centre

Geert Grooteplein Zuid 10

6525 GA, Nijmegen

The Netherlands.

Telephone: +312436 67379 
Fax: +312436 68752

Email: h.arts@antrg.umcn.nl

Word count: 2523 (excluding title page, abstract, references, figures and tables) 


\section{ABSTRACT}

\section{Background}

Sensenbrenner syndrome is a ciliopathy that is characterized by skeletal and ectodermal anomalies, accompanied by chronic renal failure, heart defects, liver fibrosis and other features.

\section{Methods}

SNP array analysis and standard sequencing techniques were applied to identify the causative gene. The effect of the identified mutation on protein translation was determined by western blot analysis. Antibodies against intraflagellar transport (IFT) proteins were used in ciliated fibroblast cell lines to investigate the molecular consequences of the mutation on ciliary transport.

\section{Results}

We performed homozygosity mapping and positional candidate gene sequence analysis in two siblings with Sensenbrenner syndrome of a consanguineous Moroccan family. In both siblings, we identified a homozygous mutation in the initiation codon of C14ORF179. C14ORF179 encodes IFT43, a subunit of the intraflagellar transport complex A (IFT-A) machinery of primary cilia. Western blots revealed that the mutation disturbs translation of IFT43, inducing the initiation of translation of a shorter protein product from a downstream ATG. The IFT-A protein complex is implicated in retrograde ciliary transport along axonemal microtubules. We show that in fibroblasts of one of the by Sensenbrenner affected siblings, disruption of IFT43 disturbs this transport from the ciliary tip to its base. As anterograde transport in the opposite direction apparently remains functional, the intraflagellar transport complex B proteins accumulate in the ciliary tip. Interestingly, we obtained similar results 
using fibroblasts from a Sensenbrenner syndrome patient with mutations in WDR35/IFT121, encoding another IFT-A subunit.

\section{Conclusions}

Our results indicate that Sensenbrenner syndrome results from disrupted IFT-A mediated retrograde ciliary transport. 


\section{INTRODUCTION}

Sensenbrenner syndrome or cranioectodermal dysplasia (CED; MIM 218330) is a rare

autosomal-recessive heterogeneous ciliopathy that is primarily characterized by skeletal abnormalities (e.g. craniosynostosis, narrow rib cage, short limbs, brachydactyly) and ectodermal defects.[1,2] Nephronophthisis leading to progressive renal failure, hepatic fibrosis, heart defects, and retinitis pigmentosa have also been described.[3-6] Recently, mutations in two genes have been found to cause Sensenbrenner syndrome, IFT122 (encoding intraflagellar transport protein 122; MIM 606045) and WDR35 (encoding WD repeat-containing protein 35; MIM 613602).[7, 8] Both genes encode proteins that are part of the intraflagellar transport (IFT) complex A (IFT-A). This multisubunit complex, consisting of at least six proteins, forms the core of a particle that is mobilized by the cytoplasmic dynein/dynactin motor. The IFT-A particles use the microtubule bundles of the ciliary axoneme to carry membrane vesicles and other "cargo" proteins from the tip of a cilium to its base (retrograde IFT).[9, 10] Both retrograde and anterograde IFT (transport towards the ciliary tip), are required for ciliary assembly, disassembly and homeostasis.[9-11]

\section{METHODS}

\section{SNP array analysis}

Genomic DNA was isolated from peripheral blood samples of two siblings with Sensenbrenner syndrome and their parents. Each DNA sample was genotyped with an Affymetrix 250K NspI array (Affymetrix, Santa Clara, CA, USA), which contains 262,000 SNPs. Array experiments were conducted according to protocols from the manufacturer. The 250K SNP genotypes were analyzed with Genotyping Console 
software (Affymetrix). PLINK[12] (available online) was used for calculation of regions of homozygosity.

\section{Mutation analysis}

Candidate genes were sequenced using patient genomic DNA. Primers for C14ORF179 and TTC8 were designed with the Primer 3 program (freely available online); primer sequences are listed in Supplemental Table 3. All coding exons of C14ORF179 and TTC8 were amplified by PCR and analyzed forward and reverse with a dye-termination chemistry (BigDye Terminator, version 3 on a 3730 DNA analyzer; Applied Biosystems). PCR conditions are available upon request.

\section{DNA constructs}

A full length cDNA clone (IRAUp969A1256 from ImaGenes) was used as a template to amplify full length C14ORF179 (NM_052873, isoform 1) with Gateway compatible primers. A consensus kozak sequence "gccgccacc" or a C14ORF179 5'UTR fragment "gtttccaggaagtgacgtcaggcggccgcggag" was included in the forward primers, just prior to the "atg". PCR products were used to create Gateway-adapted constructs by using the Gateway cloning system (Invitrogen). C14ORF179 was then cloned into two vectors, the Gateway-adapted SF-TAP vector (with a C-terminal Strep II-FLAG-tag)[13] and p504 (with a C-terminal eYFP tag).[14] Wild type constructs and vectors containing the translation initiation codon mutation were made.

\section{Transfection and western blot analysis}

HEK293T cells (human embryonic kidney) were transfected with plasmid DNA using effectene (Qiagen) in Dulbecco's modified Eagle's medium (DMEM) with 10\% Fetal 
Calf Serum (FCS) according the manufacturer's instructions. 24 hours after transfection, cells were lysed in ice cold lysis buffer (1x TBS, 0,5\% NP-40 with complete protease inhibitor cocktail, Roche). Lysates containing IFT43-eYFP and IFT-Strep II-FLAG were cleared by centrifugation at $4{ }^{\circ} \mathrm{C}$ for 10 minutes at $14,000 \mathrm{~g}$. After adding NuPAGE sample buffer with reducing agent (Invitrogen) to the samples, lysates were heated for 10 minutes at $70^{\circ} \mathrm{C}$. Samples were subsequently analyzed by SDS-PAGE (by using a NuPAGE Novex 4\%-12\% Bis-Tris SDS-PAGE gel) followed by western blotting using $\alpha$-FLAG (Flag M2 mouse monoclonal, Sigma, 1:1000) and $\alpha$-GFP (GFP mouse monoclonal, Roche, 1:1000) antibodies. IRDye800 (Rockland) goat anti-mouse $\operatorname{IgG}$ was used as a secondary antibody $(1: 10,000)$. Blots were washed with PBS with $0.1 \%$ Tween-20. Fluorescense was detected on a Li-Cor Odyssey 2.1 infrared scanner.

\section{Immunocytochemistry}

Fibroblast cells from Sensenbrenner patients (CL10-00031 and CL10-00021) and a control individual (CL10-00010) were stained with antibodies to the following proteins: IFT88 and IFT57 (rabbit polyclonal; both kindly provided by G. Pazour; 1:300 and 1:250, respectively); GT335 (mouse monoclonal; kindly provided by C. Janke; 1:1500); RPGRIP1L (guinea pig polyclonal; SNC040, 1:500),[14] and acetylated alpha-tubulin (mouse monoclonal, Zymed laboratories, 1:1000). The secondary antibodies (all from Molecular Probes) that were used are as following: anti-guinea pig IgG Alexa Fluor 568 and 488 (1:300), anti-rabbit IgG Alexa Fluor 568 and 488 (1:300) and anti-mouse IgG Alexa Fluor 405 (1:300). Fibroblast cells were seeded $(\sim 1: 3)$ on sterile cover glasses and incubated for 24 hours at standard cell culture conditions in Dulbecco's modified Eagle's medium (DMEM) with 20\% Fetal 
Calf Serum (FCS). Cells were subsequently serum-starved for 48 hours with DMEM with $0,2 \%$ FCS to stimulate cilia formation. Cells were then briefly washed in PBS and fixed in $2 \%$ paraformaldehyde in PBS for 20 minutes. Cover glasses were subsequently blocked with freshly made $2 \%$ BSA in PBS, followed by a 1 hour incubation with the primary antibody at room temperature. Cells were washed with PBS and then incubated with secondary antibodies for 30 minutes. Cover glasses with the stained cells were placed upside-down on a drop of Vectashield (Vector Laboratories) on a microscopic glass slide. Microscopic analysis was performed on a Zeiss Axio Imager Z1 fluorescene microscope (Zeiss) with an ApoTome slider. Images were processed with AxioVision (Zeiss) and Photoshop CS4 (Adobe Systems).

\section{Accession numbers and web resources}

Accession numbers of the C14ORF179 gene and a list of the web resources that were used in this study can be found in Supplementary Materials and Methods.

\section{RESULTS}

\section{Clinical studies and genotyping}

To identify additional genetic defects underlying Sensenbrenner syndrome, we conducted genome-wide homozygosity mapping by using Affymetrix $250 \mathrm{~K}$ arrays in a consanguineous family from Moroccan descent with two siblings with Sensenbrenner syndrome (family P05-1040, Figure 1 and Supplemental Table 1). Homozygosity analysis by using PLINK[12] revealed that the largest- and secondlargest homozygous regions of the affected siblings from family P05-1040 
(individuals II:1 and II:2, Table 1) are overlapping; this region was $25.2 \mathrm{Mb}$ on chromosome 14 (containing 158 annotated RefSeq genes), with SNP_A-2107558 and SNP_A-2312334 as bordering SNPs (Figure 1, Table 1 and Supplementary Table 2). Other homozygous regions shared less overlap, indicating that the genetic defect was most likely to be found in the region on chromosome 14 that contains the genes C14ORF179 and TTC8.

Given that IFT122 and WDR35, which are both associated with Sensenbrenner syndrome, are part of the IFT-A protein complex, we selected C14ORF179 as our primary candidate, as this gene encodes the human orthologue of another member of the IFT-A complex, IFT43.[9, 10] In addition, we selected TTC8 (tetratricopepteide repeat domain 8; MIM 608132) as a candidate gene. This gene encodes an IFT regulator and is disrupted in Bardet-Biedl syndrome (BBS; MIM 209900).[15, 16]

\section{Mutation detection}

Sequence analysis of candidate genes TTC 8 and C14ORF179 in the affected siblings excluded genetic defects in TTC8 as a cause of Sensenbrenner syndrome in these patients, but did reveal a homozygous variation in the translation initiation codon in exon 1 of C14ORF179 (c.1A>G) (Figure 2A). This variation cosegregates with the disorder in the family, as both (related) parents are heterozygous for this variation (Figure 2A). The c.1A $>\mathrm{G}$ variant was neither present in dbSNP, nor in 192 Dutchand 122 Moroccan control alleles, respectively, which provides further evidence for the pathogenicity of the identified mutation.

In an attempt to identify more mutations in C14ORF179, we screened this gene for mutations in four unrelated Sensenbrenner patients who did not carry WDR35 mutations. We did not identify mutations in these patients. Since homozygosity 
mapping in patients from two consanguineous Sensenbrenner families did not reveal major stretches of homozygosity in the regions containing WDR35, IFT122 or C14ORF179, it is likely that the heterogeneity in Sensenbrenner syndrome extends beyond these three genes.

\section{C14ORF179 mutation causes aberrant translation of the encoded IFT43 protein}

C14ORF179 contains 10 exons that encode two major protein isoforms derived from alternative splicing that only vary in a central segment of both isoforms (Figure 2BC). Although ATG $>$ GTG mutations have been reported to be pathogenic (e.g. in hereditary osteodystrophy,[17] Norrie disease,[18] and beta-thalassemia[19]), it has also been described that the GTG codon can be used as an initiation codon, albeit rare and inefficient.[20-22] We therefore investigated the effect of the c.1A>G mutation in C14ORF179 on its encoded protein. To test if this mutation diminishes translation or if it leads to translation initiation from a downstream ATG (most likely from the first downstream ATG in exon 2), we cloned the full length C14ORF179 cDNA with and without the c.1A>G mutation into expression vectors encoding eYFP- and Strep IIFLAG fusion tags. Western blot analysis of the recombinant tagged IFT43 proteins reveals that the translation initation codon mutation indeed disturbs translation; introduction of the mutation yields IFT43 proteins with a lower molecular weight of $\sim 3 \mathrm{kDa}$ compared to wild type proteins (Figures $2 \mathrm{D}$ and $2 \mathrm{E}$ ). This is in agreement with translation initiation at the second ATG of the coding sequence (in exon 2), at position c.A64, that becomes the first available initiation codon due to the mutation. This results in an N-terminal deletion of 21 amino acids (p.Met1_Val21del) in the same open reading frame. 


\section{Mutation in C14ORF179/IFT43 disrupts ciliary transport}

The structure of IFT43, the protein product of C14ORF179, remains largely elusive as the protein contains no significant homology with any structural or functional motifs (as determined by using SMART[23]) (Figure 2C). The protein was initially studied in Chlamydomonas reinhardtii.[9] The Chlamydomonas orthologue is part of the intraflagellar transport complex $\mathrm{A}$ that is involved in retrograde transport in the cilium.[9, 10] The IFT-A protein complex consists of IFT43, IFT121/WDR35, IFT122, IFT139, IFT140 and IFT144[10], and is associated to THM1 and TULP3.[24] Recently, it was shown that IFT43 directly binds to IFT121/WDR35, which supports a tight relationship between these two proteins.[25] This is remarkable, since IFT121/WDR35 is the protein product of WDR35, a previously identified Sensenbrenner gene.[8]

Studies in multiple species, including Chlamydomonas reinhardtii, Caenorhabditis elegans, Drosophila melanogaster and Trypanosoma brucei, have shown that disruption of retrograde transport leads to formation of bulged cilia that contain an accumulation of IFT-B complex proteins in their tips.[24, 26-30] In order to validate the disruptive effect of the identified mutation in C14ORF179 in family P05-1040 (Figures 1 and 2), we stained fibroblasts from one of the affected siblings (II:2) using antibodies against the IFT-B complex protein members IFT88 and IFT57. Indeed, we identified a similar accumulation of IFT-B complex proteins in the distal part of the ciliary axoneme and in the ciliary tip (Figure 3 and Supplementary Figures 1 and 2), while in cilia of control fibroblasts, these proteins were less abundant and primarily localized at the basal body and transition zone. 
Subsequently, we compared these ciliary defects with the phenotype of cilia in fibroblasts from a Sensenbrenner patient with WDR35 mutations (a patient that we described previously[8]), and found nearly identical defects (Fig 3 and Supplementary Figures 1 and 2). Moreover, similar to what was reported for Sensenbrenner patients with IFT122 mutations,[7] we found that cilia from patient fibroblasts (II:2, Figure) are somewhat shorter than those of healthy controls (Supplementary Figure 3).

\section{DISCUSSION}

We report on a family with two children with Sensenbrenner syndrome who carry a mutation in the translation initiation codon of C14ORF179. This is the third gene associated with Sensenbrenner syndrome and in line with the other two genes (WDR35 and IFT122), C14ORF179 also encodes a member of the IFT-A particle (IFT43). Mutations in WDR35 can cause both Sensenbrenner syndrome and the more severe (and embryonically lethal) Short Rib-Polydactyly (personal communication, P.J. Lockheart). We therefore suggest that both syndromes are part of a phenotypic spectrum of IFT-A complex disruption, similar to what has been proposed for Joubert syndrome and allied ciliopathies like Meckel-Grüber syndrome and Bardet-Biedl syndrome. The remaining protein activity then determines the severity of the disease phenotype. Indeed, in all genes associated with Sensenbrenner syndrome identified thus far, only mutations with a relatively mild disruptive character (mainly missense mutations, sometimes in combination with a truncating mutation) were identified, including the mutation described in this report which results in a small, N-terminal truncation of IFT43. In this respect, it is interesting to note that although we show that such mild mutations in cilia of Sensenbrenner patients' fibroblasts disrupt retrograde transport, they do not abrogate ciliogenesis. 
Sensenbrenner syndrome clinically overlaps with Jeune syndrome (also known as Asphyxiating Thoracic Dystrophy; ATD; MIM 208500). Skeletal anomalies such as brachydactyly, short limbs and a narrow thorax have been reported in both disorders. A skeletal characteristic that is unique for Sensenbrenner syndrome is craniosynostosis, however, only the youngest sibling in family P05-1040 displayed this typical characteristic (Supplementary Table 1, patient II:2). This complicated the initial clinical diagnosis in this family as it was unclear whether this family suffered from Sensenbrenner syndrome or a mild form of Jeune syndrome.

Like in Sensenbrenner syndrome, genes associated with Jeune syndrome encode proteins involved in ciliary transport. Mutations have been identified in IFT80 (intraflagellar transport 80; MIM 611177) that encodes an IFT-B complex protein, as well as in DYNC2H1 (dynein, cytoplasmic 2, heavy chain 1; MIM 603297) which is a retrograde motor transporting the IFT-A particle.[31, 32] Because of the clinicaland functional overlap between Sensenbrenner and Jeune syndrome, we also performed mutation analysis in 17 Jeune patients. Although we did not detect any C14ORF179 mutations in these patients, which indicates that this is not a frequent cause of Jeune syndrome, it remains a functional candidate gene.

In conclusion, we identified a homozygous mutation in the translation initiation codon in C14ORF179 that causes Sensenbrenner syndrome in a consanguineous family of Moroccan descent. The identified genetic defect interferes with translation, resulting in a shortened protein. Consistent with the disruption of a member of the IFT-A protein complex, fibroblasts from one of the affected siblings (II:2) show a typical IFT-A defect (i.e. accumulation of IFT-B complex proteins in the ciliary tip). Our 
results demonstrate that Sensenbrenner syndrome results from defects in retrograde intraflagellar transport.

\section{Acknowledgements}

We thank the Sensenbrenner and Jeune families for their participation. We also thank P.L. Beales, A.F.M. Hoogeboom, B.C.J. Hamel, I. Stolte-Dijkstra, D. Doherty and other clinicians for supplying additional Sensenbrenner and ciliopathy patients. We

thank R. Boulouiz and A. Bertoliavella for providing Moroccan control DNA samples, G. Pazour for sharing the anti-IFT88 and anti-IFT57 antibodies, and C. Janke for the GT335 antibody. We thank T. Merkx and S. van der Velde-Visser for technical assistance, and F.M.P. Cremers, A.I. den Hollander, J. Fransen, J. te Riet and M. Wijers-Rouw for helpful discussions. This research was supported by grants from the Dutch Kidney Foundation (KJPB 09.009 to H.H.A), the European Community's Seventh Framework Programme FP7/2009 under grant agreement no: 241955, SYSCILIA (to R.R.), and a grant from the Netherlands Organization for Scientific Research (NWO Vidi-91786396; to R.R.).

\section{Ethics Approval}

This study was approved by the Medical Ethics Committee of the Radboud University Nijmegen Medical Centre.

\section{Informed Consent}

Obtained. This includes written informed consent from the parents of the patients (II:1 and II:2) for publication of the images. 


\section{Competing interests}

None.

\section{Funding}

Dutch Kidney Foundation; Netherlands Organization for Scientific Research (NWO); European Community's Seventh Framework Programme FP7/2009.

\section{License for publication}

The Corresponding Author has the right to grant on behalf of all authors and does grant on behalf of all authors, an exclusive licence on a worldwide basis to the BMJ Publishing Group Ltd to permit this article (if accepted) to be published in Journal of Medical Genetics and any other BMJPGL products and sublicences such use and exploit all subsidiary rights, as set out in our license (http://group.bmj.com/products/journals/instructions-for-authors/licence-forms). 
Figure 1. Family P05-1040 is affected by Sensenbrenner syndrome. (A) P05-1040 is a consanguineous family from Moroccan descent with two siblings with Sensenbrenner syndrome. Clinical features of patient II:1 (B-F) and patient II:2 (GK). (B) Absence of typical craniofacial features. (C) Rhizomelic shortening of limbs, narrow thorax. (D) Hypoplastic, cone shaped, and widely spaced teeth. (E) Bilaterial 2-3-4 toe syndactyly. (F) Brachydactyly, webbing of fingers, short and broad nails. (G) Frontal bossing, telecanthus, micrognathia, sparse and fine hair. (H) Rhizomelic shortening of limbs, narrow thorax. Haemodialysis catheter, Ciminoshunt left arm, gastrostomy. (I) Hypoplastic and widely spaced teeth. (J) Bilateral postaxial polydactyly, bilateral 2-3 toe and 5-6 toe syndactyly, sandal gap between 1-2 toes. (K) Brachydactyly, webbing of fingers, short and broad nails after surgical correction of postaxial polydactyly. Written informed consent from the parents was obtained to publish images from patients II:1 and II:2. 
Figure 2. Mutations in C14ORF179 cause Sensenbrenner syndrome. (A) In family P05-1040, both affected siblings (II:1 and II:2, left panel) carry a homozygous mutation $(\mathrm{c} .1 \mathrm{~A}>\mathrm{G})$ in the translation initiation codon of C14ORF179. Both first cousin parents (I:1 and I:2, right panel) are heterozygous for this variation. The asterisk shows the reference sequence. (B) C14ORF179 contains 10 exons and is alternatively spliced. The mutation $(c .1 \mathrm{~A}>\mathrm{G})$ that was identified in family P05-1040 as a cause of Sensenbrenner syndrome is indicated with an asterisk. (C) Two major splice variants of C14ORF179 encode two different isoforms of IFT43 that vary in their central protein domain. (D-E) Western blot analysis of cell lysates from HEK293 cells expressing recombinant wildtype (lanes 1 and 2) and mutated IFT43 (lane 3), Cterminally fused with a Strep II-FLAG tag (left panel) or an eYFP tag (right panel). Variations of the initiation codon and upstream sequence of C14ORF179 are indicated. The initiation codon mutation interferes with translation, resulting in a shortened protein (lane 3). The difference between the mutated and the wild type protein is approximately $\sim 3 \mathrm{kDa}$ in both $\alpha$-FLAG and $\alpha$-GFP immunoblots (compare lanes 2 and 3). A wildtype construct with a kozak sequence (instead of the ' 5 UTR fragment of C14ORF179) was used as a control for protein expression. 
Figure 3. IFT 88 and IFT57 accumulate in distal ends of cilia in fibroblasts from Sensenbrenner patients with C14ORF179 and WDR35 mutations. A) Fibroblasts were stained against the IFT-B complex protein IFT88, GT335 (a marker of the proximal cilium) and RPGRIP1L (a transition zone marker). IFT88 (green); GT335 (purple); and RPGRIP1L (red). Comparison of the IFT88 staining in control fibroblasts with cells from Sensenbrenner patients reveals that IFT88 accumulates in the ciliary tips of the patient's fibroblasts. Note, that there is a certain extent of variability between IFTdefects in cilia from the patients; i.e. in some cilia the IFT88 staining is more intense (and more distal) than in others. B) Fibroblasts from Sensenbrenner patients with C14ORF179 and WDR35 mutations were stained for IFT57 (an IFT-B complex protein), and two markers that stain the base of the cilium, GT335 and RPGRIP1L. IFT57 (green); GT335 (purple); and RPGRIP1L (red). Like IFT88, IFT57 accumulates in the distal ends of cilia in fibroblasts from the patients. 
Table 1. Homozygosity mapping in Sensenbrenner family P05-1040

\begin{tabular}{|c|c|c|c|c|c|c|}
\hline Patient & Chromosome & $\begin{array}{l}\text { Bordering SNP } \\
\left(5^{\prime}\right)\end{array}$ & $\begin{array}{l}\text { Bordering SNP } \\
\text { (3') }\end{array}$ & $\begin{array}{l}\text { Size of } \\
\text { region } \\
(\mathrm{Mb})\end{array}$ & $\begin{array}{l}\text { \# SNPs in } \\
\text { homozygous } \\
\text { region }\end{array}$ & $\begin{array}{l}\text { Homozygous } \\
\text { region (i.e.1 = } \\
\text { largest, } 2= \\
\text { second largest) }\end{array}$ \\
\hline II:1 & 14 & SNP_A-2107558 & SNP_A-1781135 & 25.3 & 2425 & 1 \\
\hline \multirow[t]{2}{*}{ II: 2} & 14 & SNP_A-2107558 & SNP_A-2312334 & 25.2 & 2398 & 2 \\
\hline & & & overlap & 25.2 & & \\
\hline II: 1 & 2 & SNP_A-2123667 & SNP_A-1865387 & 2.7 & 407 & 11 \\
\hline \multirow[t]{2}{*}{ II:2 } & 2 & SNP_A-1959026 & SNP_A-2248948 & 18.8 & 2130 & 5 \\
\hline & & & overlap & 2.6 & & \\
\hline II: 1 & 11 & SNP_A-1895498 & SNP_A-4197277 & 6.0 & 271 & 6 \\
\hline \multirow[t]{2}{*}{ II:2 } & 11 & SNP_A-2268220 & SNP_A-4197277 & 6.0 & 276 & 11 \\
\hline & & & overlap & 6.0 & & \\
\hline II: 1 & 11 & SNP_A-4204835 & SNP_A-2142191 & 4.1 & 408 & 9 \\
\hline \multirow[t]{2}{*}{ II: 2} & 11 & SNP_A-4204835 & SNP_A-4205202 & 4.1 & 407 & 14 \\
\hline & & & overlap & 4.1 & & \\
\hline II: 1 & 3 & SNP_A-1923781 & SNP_A-2252922 & 1.4 & 95 & 18 \\
\hline \multirow[t]{2}{*}{ II:2 } & 3 & SNP_A-1820067 & SNP_A-1974247 & 5.1 & 394 & 13 \\
\hline & & & overlap & 1.4 & & \\
\hline II:1 & 3 & SNP_A-1972308 & SNP_A-1829330 & 1.1 & 108 & 24 \\
\hline \multirow[t]{2}{*}{ II:2 } & 3 & SNP_A-1972309 & SNP_A-1972369 & 2.0 & 209 & 17 \\
\hline & & & overlap & 1.0 & & \\
\hline II: 1 & 17 & SNP_A-2206444 & SNP_A-1872313 & 1.1 & 71 & 23 \\
\hline \multirow[t]{2}{*}{ II:2 } & 17 & SNP_A-2302032 & SNP_A-2156489 & 1.1 & 73 & 23 \\
\hline & & & overlap & 1.1 & & \\
\hline II: 1 & 5 & SNP_A-4210912 & SNP_A-4202173 & 1.0 & 54 & 28 \\
\hline \multirow[t]{2}{*}{ II:2 } & 5 & SNP_A-2084301 & SNP_A-2293403 & 1.1 & 64 & 22 \\
\hline & & & overlap & 1.0 & & \\
\hline
\end{tabular}


Reference List

(1) Sensenbrenner JA, Dorst JP, Owens RP. New syndrome of skeletal, dental and hair anomalies. Birth Defects Orig Artic Ser 1975;11(2):372-9.

(2) Levin LS, Perrin JC, Ose L, Dorst JP, Miller JD, McKusick VA. A heritable syndrome of craniosynostosis, short thin hair, dental abnormalities, and short limbs: cranioectodermal dysplasia. J Pediatr 1977 Jan;90(1):55-61.

(3) Amar MJ, Sutphen R, Kousseff BG. Expanded phenotype of cranioectodermal dysplasia (Sensenbrenner syndrome). Am J Med Genet 1997 Jun 27;70(4):349-52.

(4) Fry AE, Klingenberg C, Matthes J, Heimdal K, Hennekam RC, Pilz DT. Connective tissue involvement in two patients with features of cranioectodermal dysplasia. Am J Med Genet A 2009 Oct;149A(10):2212-5.

(5) Konstantinidou AE, Fryssira H, Sifakis S, Karadimas C, Kaminopetros P, Agrogiannis G, Velonis S, Nikkels PG, Patsouris E. Cranioectodermal dysplasia: a probable ciliopathy. Am J Med Genet A 2009 Oct;149A(10):2206-11.

(6) Zaffanello M, omedi-Camassei F, Melzi ML, Torre G, Callea F, Emma F. Sensenbrenner syndrome: a new member of the hepatorenal fibrocystic family. Am J Med Genet A 2006 Nov 1;140(21):2336-40.

(7) Walczak-Sztulpa J, Eggenschwiler J, Osborn D, Brown DA, Emma F, Klingenberg C, Hennekam RC, Torre G, Garshasbi M, Tzschach A, Szczepanska M, Krawczynski M, Zachwieja J, Zwolinska D, Beales PL, Ropers HH, Latos-Bielenska A, Kuss AW. Cranioectodermal Dysplasia, Sensenbrenner syndrome, is a ciliopathy caused by mutations in the IFT122 gene. Am J Hum Genet 2010 Jun 11;86(6):949-56.

(8) Gilissen C, Arts HH, Hoischen A, Spruijt L, Mans DA, Arts P, van LB, Steehouwer M, van RJ, Kant SG, Roepman R, Knoers NV, Veltman JA, Brunner HG. Exome sequencing identifies WDR35 variants involved in Sensenbrenner syndrome. Am J Hum Genet 2010 Sep 10;87(3):418-23.

(9) Piperno G, Siuda E, Henderson S, Segil M, Vaananen H, Sassaroli M. Distinct mutants of retrograde intraflagellar transport (IFT) share similar morphological and molecular defects. J Cell Biol 1998 Dec 14;143(6):1591601.

(10) Cole DG. The intraflagellar transport machinery of Chlamydomonas reinhardtii. Traffic 2003 Jul;4(7):435-42.

(11) Kozminski KG, Beech PL, Rosenbaum JL. The Chlamydomonas kinesin-like protein FLA10 is involved in motility associated with the flagellar membrane. J Cell Biol 1995 Dec;131(6 Pt 1):1517-27.

(12) Purcell S, Neale B, Todd-Brown K, Thomas L, Ferreira MA, Bender D, Maller J, Sklar P, de Bakker PI, Daly MJ, Sham PC. PLINK: a tool set for whole- 
genome association and population-based linkage analyses. Am J Hum Genet 2007 Sep;81(3):559-75.

(13) Gloeckner CJ, Boldt K, Schumacher A, Roepman R, Ueffing M. A novel tandem affinity purification strategy for the efficient isolation and characterisation of native protein complexes. Proteomics 2007 Dec;7(23):4228-34.

(14) Arts HH, Doherty D, van Beersum SE, Parisi MA, Letteboer SJ, Gorden NT, Peters TA, Marker T, Voesenek K, Kartono A, Ozyurek H, Farin FM, Kroes HY, Wolfrum U, Brunner HG, Cremers FP, Glass IA, Knoers NV, Roepman R. Mutations in the gene encoding the basal body protein RPGRIP1L, a nephrocystin-4 interactor, cause Joubert syndrome. Nat Genet 2007 Jul;39(7):882-8.

(15) Ansley SJ, Badano JL, Blacque OE, Hill J, Hoskins BE, Leitch CC, Kim JC, Ross AJ, Eichers ER, Teslovich TM, Mah AK, Johnsen RC, Cavender JC, Lewis RA, Leroux MR, Beales PL, Katsanis N. Basal body dysfunction is a likely cause of pleiotropic Bardet-Biedl syndrome. Nature 2003 Oct 9;425(6958):628-33.

(16) Ou G, Blacque OE, Snow JJ, Leroux MR, Scholey JM. Functional coordination of intraflagellar transport motors. Nature 2005 Jul 28;436(7050):583-7.

(17) Patten JL, Johns DR, Valle D, Eil C, Gruppuso PA, Steele G, Smallwood PM, Levine MA. Mutation in the gene encoding the stimulatory $G$ protein of adenylate cyclase in Albright's hereditary osteodystrophy. N Engl J Med 1990 May 17;322(20):1412-9.

(18) Isashiki Y, Ohba N, Yanagita T, Hokita N, Doi N, Nakagawa M, Ozawa M, Kuroda N. Novel mutation at the initiation codon in the Norrie disease gene in two Japanese families. Hum Genet 1995 Jan;95(1):105-8.

(19) Hattori Y, Yamashiro Y, Ohba Y, Miyaji T, Morishita M, Yamamoto K, Yamamoto K, Narai S, Kimura A. A new beta-thalassemia mutation (initiation codon ATG---GTG) found in the Japanese population. Hemoglobin 1991;15(4):317-25.

(20) Touriol C, Bornes S, Bonnal S, Audigier S, Prats H, Prats AC, Vagner S. Generation of protein isoform diversity by alternative initiation of translation at non-AUG codons. Biol Cell 2003 May;95(3-4):169-78.

(21) Chen SJ, Ko CY, Yen CW, Wang CC. Translational efficiency of redundant ACG initiator codons is enhanced by a favorable sequence context and remedial initiation. J Biol Chem 2009 Jan 9;284(2):818-27.

(22) Hwang SR, Garza CZ, Wegrzyn JL, Hook VY. Demonstration of GTG as an alternative initiation codon for the serpin endopin 2B-2. Biochem Biophys Res Commun 2005 Feb 18;327(3):837-44.

(23) Schultz J, Milpetz F, Bork P, Ponting CP. SMART, a simple modular architecture research tool: identification of signaling domains. Proc Natl Acad Sci U S A 1998 May 26;95(11):5857-64. 
(24) Mukhopadhyay S, Wen X, Chih B, Nelson CD, Lane WS, Scales SJ, Jackson PK. TULP3 bridges the IFT-A complex and membrane phosphoinositides to promote trafficking of $\mathrm{G}$ protein-coupled receptors into primary cilia. Genes Dev 2010 Oct 1;24(19):2180-93.

(25) Cole DG, Snell WJ. SnapShot: Intraflagellar transport. Cell 2009 May $15 ; 137(4): 784$.

(26) Iomini C, Babaev-Khaimov V, Sassaroli M, Piperno G. Protein particles in Chlamydomonas flagella undergo a transport cycle consisting of four phases. $\mathbf{J}$ Cell Biol 2001 Apr 2;153(1):13-24.

(27) Iomini C, Li L, Esparza JM, Dutcher SK. Retrograde intraflagellar transport mutants identify complex A proteins with multiple genetic interactions in Chlamydomonas reinhardtii. Genetics 2009 Nov;183(3):885-96.

(28) Blacque OE, Li C, Inglis PN, Esmail MA, Ou G, Mah AK, Baillie DL, Scholey JM, Leroux MR. The WD repeat-containing protein IFTA-1 is required for retrograde intraflagellar transport. Mol Biol Cell 2006 Dec;17(12):5053-62.

(29) Absalon S, Blisnick T, Kohl L, Toutirais G, Dore G, Julkowska D, Tavenet A, Bastin P. Intraflagellar transport and functional analysis of genes required for flagellum formation in trypanosomes. Mol Biol Cell 2008 Mar;19(3):929-44.

(30) Tran PV, Haycraft CJ, Besschetnova TY, Turbe-Doan A, Stottmann RW, Herron BJ, Chesebro AL, Qiu H, Scherz PJ, Shah JV, Yoder BK, Beier DR. THM1 negatively modulates mouse sonic hedgehog signal transduction and affects retrograde intraflagellar transport in cilia. Nat Genet 2008 Apr;40(4):403-10.

(31) Beales PL, Bland E, Tobin JL, Bacchelli C, Tuysuz B, Hill J, Rix S, Pearson CG, Kai M, Hartley J, Johnson C, Irving M, Elcioglu N, Winey M, Tada M, Scambler PJ. IFT80, which encodes a conserved intraflagellar transport protein, is mutated in Jeune asphyxiating thoracic dystrophy. Nat Genet 2007 Jun;39(6):727-9.

(32) Dagoneau N, Goulet M, Genevieve D, Sznajer Y, Martinovic J, Smithson S, Huber C, Baujat G, Flori E, Tecco L, Cavalcanti D, Delezoide AL, Serre V, Le MM, Munnich A, Cormier-Daire V. DYNC2H1 mutations cause asphyxiating thoracic dystrophy and short rib-polydactyly syndrome, type III. Am J Hum Genet 2009 May;84(5):706-11. 
Figure 1
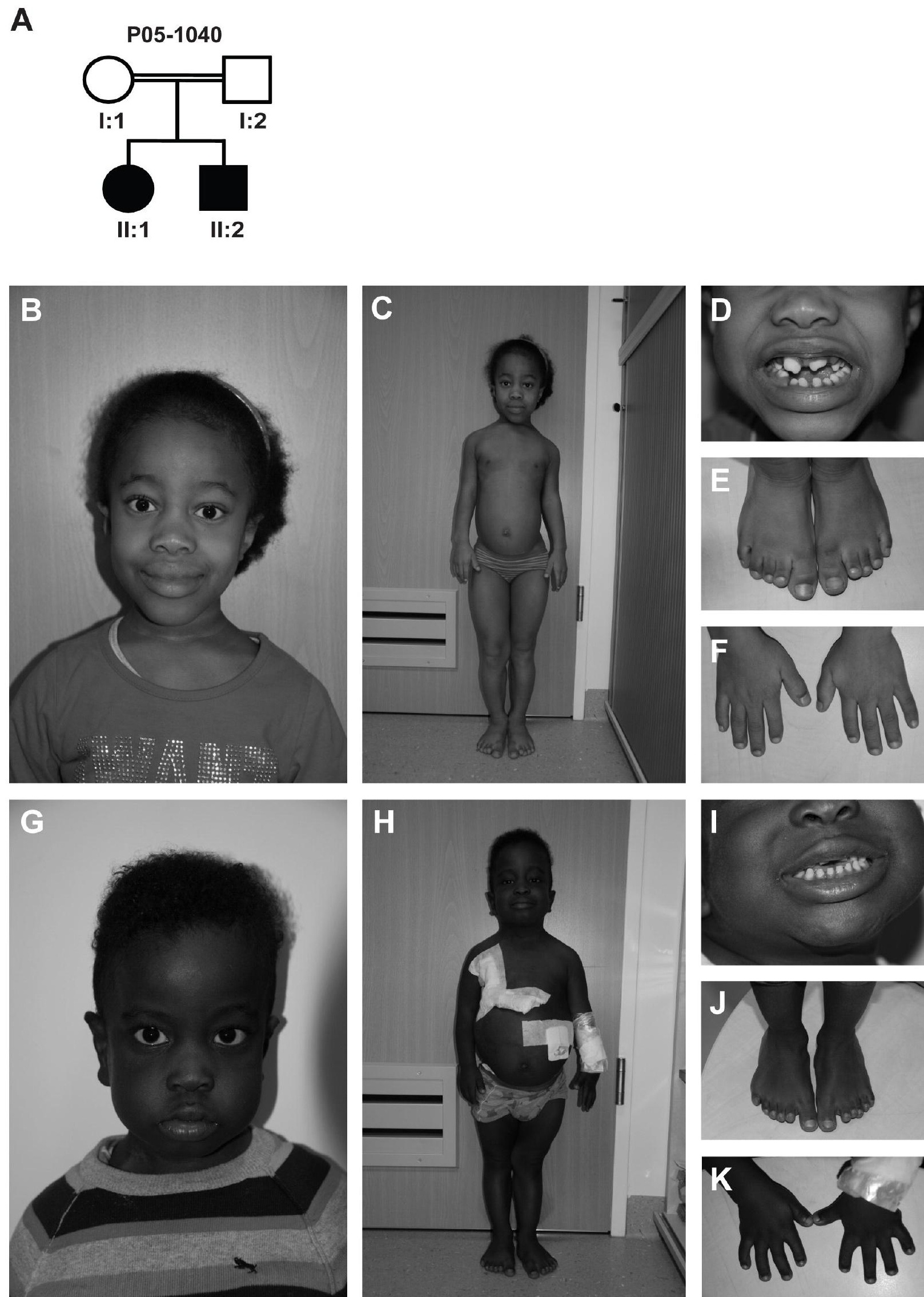


\section{Figure 2}

A $\quad G G$ i G

$G G$ is $G \quad G$ T $G$ G is

II:1

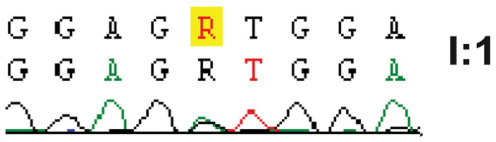

$G G$ i $G \quad G \quad T \quad G \quad G \quad \underline{L}$

$G \quad G$ il $G$ R $T$ G $G$ i

$G G$ I $G$ R $T$ T $G$ G

I:2

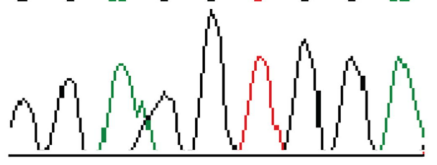

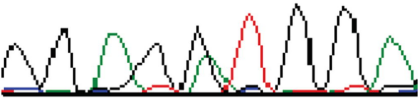

$G$ G I $G G$ T G G I

$G$ G I $G$ G $T$ G $G$ I

II:2

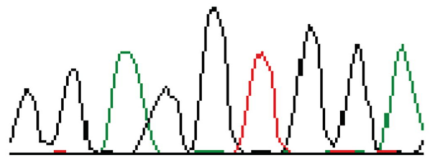

B $\underline{\text { C140RF179 }}$

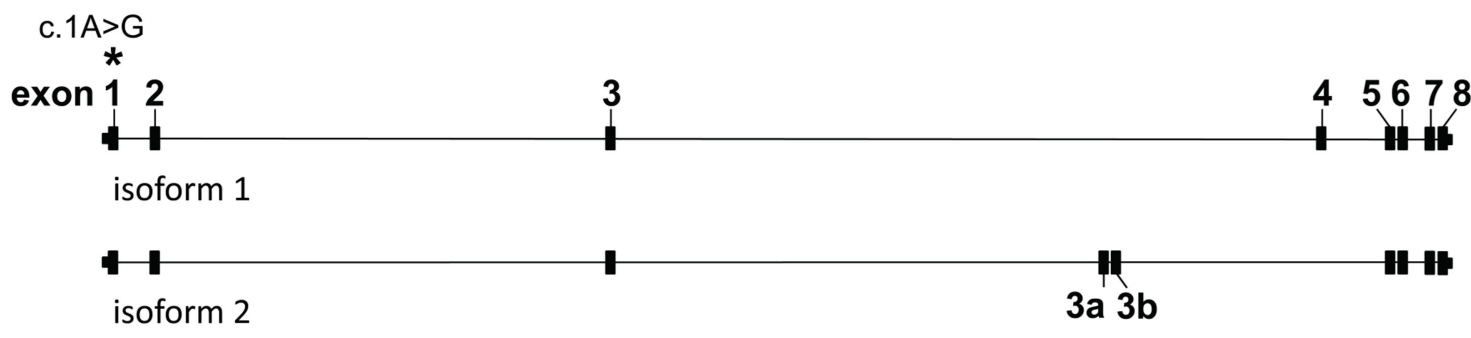

C $\quad$ IFT43
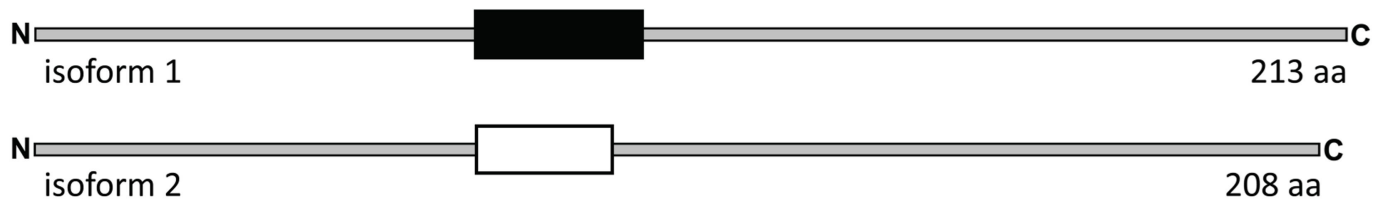

D

E
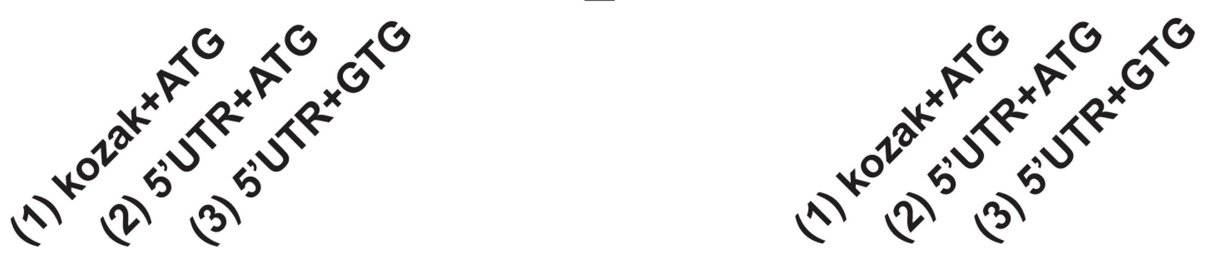

$37=$

IB: $\alpha-F L A G$

IB: $\alpha-G F P$ 


\section{Figure 3}

A

control

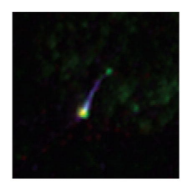

patient II:2
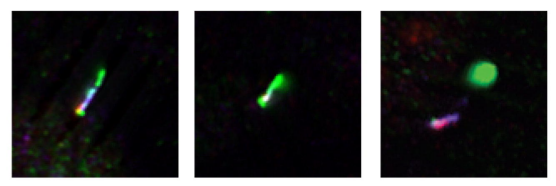

IFT88

GT335

RPGRIP1L

control

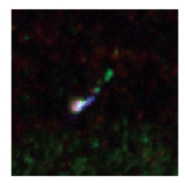

B

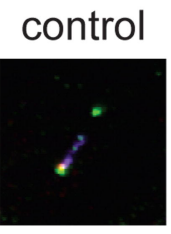

control

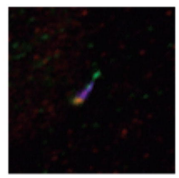

patient with mutated WDR35
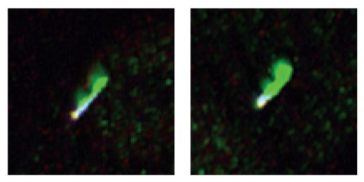

IFT88

GT335

RPGRIP1L patient II:2
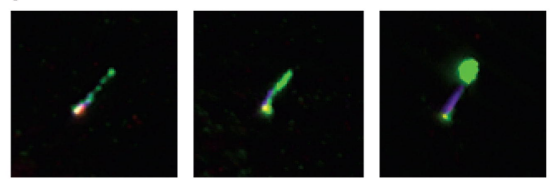

IFT57

GT335

RPGRIP1L 